This item was submitted to Loughborough's Research Repository by the author.

Items in Figshare are protected by copyright, with all rights reserved, unless otherwise indicated.

\title{
Reliability of the spherical agglomerate models for catalyst layer in polymer electrolyte membrane fuel cells
}

PLEASE CITE THE PUBLISHED VERSION

http://dx.doi.org/10.1016/j.electacta.2014.04.060

\section{PUBLISHER}

(C) Elsevier

VERSION

AM (Accepted Manuscript)

\section{PUBLISHER STATEMENT}

This work is made available according to the conditions of the Creative Commons Attribution-NonCommercialNoDerivatives 4.0 International (CC BY-NC-ND 4.0) licence. Full details of this licence are available at: https://creativecommons.org/licenses/by-nc-nd/4.0/

\section{LICENCE}

CC BY-NC-ND 4.0

\section{REPOSITORY RECORD}

Zhang, Xiaoxian, Hossein Ostadi, Kyle Jiang, and Rui Chen. 2014. "Reliability of the Spherical Agglomerate Models for Catalyst Layer in Polymer Electrolyte Membrane Fuel Cells". figshare. https://hdl.handle.net/2134/15616. 


\title{
Reliability of the spherical agglomerate model for catalyst layer in proton exchange membrane fuel cell
}

\author{
Xiaoxian Zhang ${ }^{\text {a }}$, Hossein Ostadi ${ }^{\mathrm{b}}$, Kyle Jiang ${ }^{\mathrm{b}}$, Rui Chen ${ }^{\mathrm{c}}$ \\ a School of Engineering, University of Liverpool, Brownlow Street, Liverpool, L69 3GQ UK. \\ e-mail: Xiaoxian.zhang@liverpool.ac.uk \\ b Intelligent Energy, Charnwood Building, Holywell park, Loughborough, Leicestershire, \\ LE11 3GB, UK. e-mail: Hossein.Ostadi@intelligent-energy.com \\ ${ }^{\mathrm{c}}$ Department of Aeronautical and Automotive Engineering, Loughborough University, \\ Leicestershire LE11 3TU, UK. e-mail: R.Chen@lboro.ac.uk
}




\begin{abstract}
The spherical agglomerate model with a single diameter is a common approach to describe the average electrochemical reaction rate in the catalyst layer of PEM fuel cells. Real agglomerates are highly irregular, and approximating them by independent spheres could give rise to errors. In this paper, we investigated these errors using nanotomography and numerical simulations. Three-dimensional microstructure of a cathode catalyst layer was acquired using FIB/SEM nanotomography, and oxygen diffusion and the associated electrochemical reaction in the microstructure were simulated using pore-scale modelling. The simulated concentration and reaction rates at the pore scale were volumetrically averaged to obtain the average reaction rates. These simulated average reaction rates were then compared with the results predicted by the spherical agglomerate model using an average diameter estimated from the 3D microstructure. The comparisons revealed that the spherical agglomerate model substantially overestimated the reaction rates when the overpotential is high because of its incorrect description of the contact areas between the agglomerates and the macropores through which the oxygen diffuses. We also fitted the spherical agglomerate model to the simulated reaction rates by treating its diameter as a fitting parameter. The results showed that the value of the diameter needs to increase with the overpotential in order to match the simulated data. These findings implicate that the spherical agglomerate model needs to be used with care in catalyst layer design as its diameter is just a fitting parameter rather than a geometrical description of the agglomerates.
\end{abstract}

Key words: PEM fuel cells; catalyst layer; FIB/SEM nanotomography; agglomerate model; microscopic modelling 


\begin{tabular}{|cl|}
\hline Nomenclature \\
$\mathrm{C}$ & $\quad$ concentration of dissolved oxygen in agglomerate \\
$\mathrm{C}_{0}$ & concentration of dissolved oxygen on outer surface of the thin \\
& ionomer film coated on the agglomerate surface \\
$\mathrm{C}_{\mathrm{ref}}$ & reference dissolved oxygen concentration \\
$\mathrm{D}_{0}$ & diffusion coefficient of dissolved oxygen in ionomer \\
$\mathrm{D}_{\mathrm{eff}}$ & effective diffusion coefficient of dissolved oxygen in agglomerate \\
$\mathrm{F}$ & Faraday constant \\
$\mathrm{i}_{\mathrm{ref}}$ & reference exchange current density \\
$\mathrm{T}$ & temperature \\
$\mathrm{r}_{0}$ & local oxygen reduction rate in agglomerate \\
$\mathrm{r}_{\mathrm{gg}}$ & radius of spherical agglomerate \\
$\mathrm{R}$ & gas constant \\
$\mathrm{R}_{0}$ & volumetric average oxygen reduction rate in agglomerate \\
$\mathrm{S}_{\mathrm{a}}$ & volumetric reactive surface area of the catalyst in agglomerate \\
$\mathrm{V}_{\mathrm{i}}$ & volume of each voxel in 3D image of the catalyst layer \\
$\alpha_{\mathrm{c}}$ & cathodic transfer coefficient \\
$\eta$ & overpotential \\
$\delta$ & thickness of the thin ionomer film coated on agglomerate surface \\
\hline
\end{tabular}




\section{Introduction}

The catalyst layer in polymer electrolyte membrane (PEM) fuel cell is the area where all the electrochemical reactions take place and hence plays a central role in cell performance (Zhang et al., 2009). At the anode, the hydrogen is oxidised into proton and electron, whilst at the cathode the proton reacts with oxygen and electron to form water (Wang et al., 2011). It is believed that the sluggish oxygen reduction and the associated species transport in the cathode catalyst layer are the key limitation in cell performance(Wang et al., 2007), and increasing catalyst layer efficiency and durability is a challenge in PEM fuel cell design and manufacturing (Balgis et al., 2012; Yu et al., 2011).

The most common catalyst used in PEM fuel cells is platinum supported by carbon grains (Thiele et al., 2013). The carbon grains are further bound by an ionomer. In manufacturing and cell operation, the carbon grains tend to aggregate, making the catalyst layer a bi-mode porous medium with micropores inside the agglomerates and macropores between (Siddique and Liu, 2010). The average size of the macropores ranges from $60 \mathrm{~nm}$ (Thiele et al., 2011; Ziegler et al., 2011) to $188 \mathrm{~nm}$ (Epting et al., 2012), depending on the technologies used for visualization. Whilst the macropores provide pathways for oxygen to diffuse from the gas diffusion layer to the catalyst layer, it is the micropores inside the agglomerates that transport the oxygen to the catalyst where the electrochemical reaction takes place. Species transport and the associated electrochemical reaction in the cathode catalyst layer are the most complicated processes in PEM fuel cells as they involve both liquid water and gaseous species (Hutzenlaub et al., 2013).

The electrochemical reaction in the catalyst layer is local, occurring only in the presence of the catalyst, electrolyte and oxygen; it is difficult to measure because of their opaque nature. As a result, mathematical models have been increasingly used over the past few years to bridge this gap. In practical fuel cell modelling, the individual agglomerates cannot be 
explicitly resolved, and the electrochemical reaction occurring within them is hence solved by volumetric average known as catalyst models in the literature (Broka and Ekdunge, 1997). The available catalyst models can be classified into thin-film model, homogenous model and agglomerate model (Harvey et al., 2008). The thin-film and the homogeneous models assume the potential loss due to species diffusion in the catalyst layer is negligible. They do not involve any parameters related to catalyst layer structure, and hence cannot be used for catalyst layer design. The agglomerate model is an improved approach, developed under the recognition that species diffusion through the nano-pores in the agglomerates is slow and could become a limiting factor to the electrochemical reaction under high electrical current, as demonstrated by both theory and experiments (Gloaguen and Durand, 1997; MoeinJahromi and Kermani, 2012). With a few exceptions (Xia et al., 2008), the most common agglomerate model is based on the work of Thiele assuming that the catalyst layers is a packing of non-overlapped spherical agglomerates (Thiele, 1939). Since species diffusion in a spherical agglomerate depends on its porosity and the electrochemical reaction rate occurring on the surface area of the catalyst, the spherical agglomerate model naturally links cell performance to catalyst loading, agglomerate size and volumetric ionomer content in the catalyst layer, and can thus help design (Das et al., 2008).

The earlier spherical agglomerate model assumed a direct contact between the agglomerate surface and the reactants in the macropores, with the agglomerates either fully saturated by ionomer or by liquid water (Wang et al., 2004a; Wang et al., 2004b). From the way the catalyst layer is fabricated, however, it is more likely that the agglomerate has a thin ionomer film coated over its surface. Based on this, Sun et al. (Sun et al., 2005) proposed an improved approach assuming that the oxygen needs to dissolve in the ionomer coating first prior to diffusing into the agglomerate. Since then, this model has been widely used in fuel cell modelling (Kamarajugadda and Mazumder, 2012; Suzuki et al., 2013). 
The attraction of the spherical agglomerate model is its simplicity as there is a closedform analytical solution for the volumetric reaction rate. Microscopies of real catalyst layers, however, have revealed that the agglomerate geometry is highly irregular (Liu et al., 2003; Ziegler et al., 2011), and approximating it by isolated spheres as assumed in the spherical model could give rise to considerable errors. To evaluate the accuracy of the spherical agglomerate model with a single diameter, Epting et al. (Epting and Litster, 2012) assumed that the catalyst layer was composed of independent spheres with different diameters, and the diameter of each sphere was determined from the 3D X-ray image of a commercial catalyst layer. The surface of each sphere was assumed to be coated by a thin ionomer film which is in direct contact with the reactants in the macropores. Their results showed that using the spherical agglomerate model, it is impossible to find an effective agglomerate diameter which can describe the volumetric reaction rate for overpotential in the range from 0 to $1.0 \mathrm{~V}$.

Species diffusion and the associated electrochemical reaction in the catalyst layer are controlled by geometry of the pores both inside and outside the agglomerates. Since species diffusion and electrochemical reaction are difficult to visualize and measure, pore-scale modelling has been increasingly used over the past few years to gain some insight into the processes occurring in the catalyst layer which affect cell performance. The earlier pore-scale models idealised the catalyst layer either as a regular lattice with the spheres sitting at the nodes (El Hannach et al., 2012; Wu et al., 2012), or as a random packing of the three phases ionomer, pore and carbon grains. These models could not correctly represent the irregular aggregations of the carbon grains (Wang et al., 2007).

The development in imaging technology over the past few years has made visualization of interior structure of opaque materials possible at resolutions as fine as a few nanometres. These technologies have been used by us and other groups to visualize gas diffusion layers and catalyst layers in PEM fuel cells (Ostadi et al., 2010; Wargo et al., 2013). For example, 
using X-ray computed tomography or focused ion beam/scanning electron microscopy (FIB/SEM), one can visualise the interior structure of the catalyst layer at resolutions from 100 nanometres to a few nanometres (Epting et al., 2012; Zils et al., 2010). These, together with the SEM imaging technology, can unravel the catalyst layer structure and locate the distribution of the catalyst in the agglomerates (Thiele et al., 2013). There has been a surge in use of FIB/SEM nanotomography over the past few years to simulate the detailed species transport in the catalyst layer (Lange et al., 2012).

The purpose of this paper is to investigate the accuracy and reliability of the commonly used spherical agglomerate models based on nanotomography and numerical simulations. The interior structure of a commercial catalyst layer was acquired using FIB/SEM technology at resolution of a few nanometres in three dimensions, and oxygen diffusion and reduction in the 3D structure were simulated using a pore-scale model we previously developed (Zhang et al., 2010). The FIB/SEM cannot differentiate the ionomer and the carbon grains, and we hence numerically coated a thin ionomer film over the agglomerate surfaces in the acquired image based on its thickness reported in the literature. The volumetric oxygen reduction rate was calculated by averaging the simulated reduction rates at the pore scale over all of the voxels. We then compared the average reaction rates simulated under different overpotentials with the results predicted by the spherical agglomerate model with its diameters estimated from the 3D microstructure.

\section{Materials and methods}

\subsection{FIB/SEM imaging}

Details of the FIB/SEM technologies used for imaging microporous layer and catalyst layer of PEM fuel cells were given in previous work by us and others (Ostadi et al., 2010; Ziegler et al., 2011). For completeness, however, we briefly describe them in the following. 
In the process, a FIB/SEM system was used to obtain the 3D structure of mesoporous samples (Joos et al., 2012; Porta et al., 2013; Siddique and Liu, 2010; Thiele et al., 2011; Wu et al., 2012; Zils et al., 2010). The process involves milling away a slice of the sample as thin as $10 \sim 15 \mathrm{~nm}$ from the side wall of a trench using FIB, and taking an SEM image of the new surface as illustrated in Figure 1. Then the milling and imaging cycle is repeated to produce a stack of 2D SEM images. Next, SEM images are all aligned in reference to a fiducial mark milled prior to the milling of the thin slices. The fiducial mark need to remain sharp and undistorted in each slice/image. Furthermore, it should be as tiny as possible to occupy only a small region of the SEM image at high magnifications. The current fiducial marking techniques invoke a large area which hampers imaging at high magnifications. These fiducial marks are also distorted during FIB imaging $[3,5]$. The problem can be resolved by milling a vertical slot close to the trench and position it out of the ion beam window as shown in Figure 1. Moreover, the bombardment of FIB tends to damage the underneath layer of the soft porous materials and deform the porous structure. To overcome such problems, a metal layer can be coated on the top of the sample and the sample is milled vertically. The metal layer also serves to suppressing curtaining effects. In this way, the damaged porous structures are removed, leaving the original structures intact for SEM imaging. Meanwhile, SEM images with a resolution of a few nanometres have enabled the technique.

\subsection{Experiments}

The PEFC catalyst layer (CL) supplied by JMFC (Johnson Matthey Fuel Cells Ltd., UK) were used in this study. The CL consist of carbon supported platinum and ionomer, with platinum loading of $0.45 \mathrm{mg} / \mathrm{cm}^{2}$.

The FIB/SEM nanotomography process (FEI Dual Beam Strata 235, Oregon, US: FEI Company) started with a deposition of $100 \mathrm{~nm}$ thick platinum layer on the top surface of CL in order to protect the soft CL material from the ion bombardment and to reduce the re- 
deposition effect of FIB-induced decomposition of precursor gases. A slot as a fiducial mark was then milled for image alignment. The tiny slot is positioned out of the ion beam window to minimize the FIB damage effect. Next, each slice of the sample was milled-off using a $\mathrm{Ga}^{+}$ ion beam at $30 \mathrm{kV}$ and $30 \mathrm{pA}$ current with the FIB/SEM system. 100 slices with a total thickness of $1 \mu \mathrm{m}$ were removed and SEM images of the slices were taken. 2D images were then vertically stretched by a factor of 1.27 to compensate the SEM projection angle. Images are then finely aligned based on the fiducial mark with Lucas-Kanade algorithm [21] using Adobe Photoshop CS3 (www.adobe.com). Aligned images are thresholded to distinguish the solid network from the pore network through Otsu algorithm [22]. Finally, binary 2D images were assembled together to build a 3D binary image with 1 and 0 representing solid and pore phases respectively using the CTan software (www.skyscan.be). Figure 2 shows an anode catalyst layer and a cathode catalyst layers obtained using the above technology. Because of computer power limitation, we only took a part of the image for simulation. Since the FIB/SEM tomography cannot distinguish the ionomer coating and the agglomerate, we hence numerically coated a thin ionomer film over the agglomerate surface based on the ratio between the average agglomerate size and the thickness of the ionomer film as reported in the literature(Kamarajugadda and Mazumder, 2008). After the ionomer coating, the volumetric fraction of the macropores is $30 \%$ to be consistent with the value reported in the literature (Thiele et al., 2011). Figure 3A shows the simulated image with the numerically coated ionomer, and Figure 3B is a 2D slice in the image. It is evident from both the 2D slice and the 3D image that the agglomerates are highly irregular.

\subsection{The models}

The transport processes in the cathode catalyst layer involve electron conduction in the carbon grains, oxygen diffusion and proton conduction in the ionomer and water, and water formation and movement in the void space. Since the purpose of this work is to investigate 
the accuracy and reliability of the commonly used spherical agglomerate models, following Wang et al. (Wang et al., 2004a) we focused on a simple scenario in which the outer surface of the agglomerate was assumed to be coated by a thin ionomer film and the microscopic pores inside the agglomerates were saturated by ionomer. Furthermore, the macropores between the agglomerates were assumed to be filled by gas and the gaseous oxygen concentration was assumed to be in equilibrium with the dissolved oxygen concentration in the ionomer film. This requires the oxygen to dissolve in the ionomer film first prior to diffusing into the agglomerates.

Carbon and platinum have a good electronic conductivity and the ohmic loss due to electron conduction in them is in the order of $10^{-7} \mathrm{~V}$, negligible in comparison with the electrode potential in the order of $10^{-1} \mathrm{~V}$ (Wang et al., 2004a). The experimental observations of Gode et al. (Gode et al., 2003) revealed that the resistance of ionomer to proton conduction is very small. Thus, for agglomerates saturated with ionomer, the ohmic loss due to proton transport is also negligible. As a result, the potentials of electrons and protons in the simulated image shown in Figure 3 are constants, and the only limiting factor to electrochemical reaction is oxygen diffusion. Transport and reaction of the oxygen in the agglomerates shown in Figure 3 were modelled by the following equation assuming the diffusion and reaction were at steady state:

$D_{\text {eff }} \nabla^{2} c=r_{0}=-k_{c} c$,

where c is the dissolved oxygen concentration in the ionomer inside the agglomerates, $D_{\text {eff }}$ is the effective diffusion coefficient of the agglomerate for dissolved oxygen, and $r_{o}$ is the local volumetric oxygen reduction rate in which the kinetic rate $k_{\mathrm{c}}$ is described by the following Butler-Volmer equation:

$k_{c}=\frac{S_{a} i_{\text {ref }}}{4 F c_{\text {ref }}}\left[\exp \left(\frac{\alpha_{c} F}{R T} \eta\right)-\exp \left(-\frac{\left(1-\alpha_{c}\right) F}{R T} \eta\right)\right]$. 
In Equation (2), $S_{a}$ is the electrochemically active surface area of the catalyst in a unit volume of the agglomerate, $F$ is Faraday constant, $i_{\text {ref }}$ is reference exchange current density, $c_{\text {ref }}$ is reference oxygen concentration, $\alpha_{c}$ is cathode transfer coefficient, $T$ is temperature, $R$ is gas constant, and $\eta$ is overpotential - the difference between the potentials of protons and electrons, which, for the reasons explained above, is a constant in our simulations. The boundary associated with the transport and reactions of oxygen in the above equation is the interfaces between the macropores and the outer surface of the thin ionomer film coating over the outer surface of the agglomerates, i.e., the interfaces between the red area and the blue area shown in Figure 3. The concentration of oxygen at these interfaces was assumed to be constant and will be represented by $\mathrm{c}_{0}$ in the following analysis.

\subsection{Numerical solution and volumetric oxygen reduction rate}

Oxygen diffusion and reduction in the agglomerates shown in Figure 3 were simulated by a numerical model we previously developed for pore-scale simulation of water flow and chemical transport in soils and rocks (Zhang et al., 2010). The values of the parameters used in all simulations are given in Table 1. In each simulation, the oxygen concentration and its reaction rate in each voxel of the $3 \mathrm{D}$ image were sampled, and the volumetric average oxygen reduction rate was then calculated as follows:

$$
R_{0}=\frac{\sum_{i=1}^{N} V_{i} k_{c} c_{i}}{\sum_{i=1}^{N} V_{i}},
$$

where $c_{i}$ and $V_{i}$ are the oxygen concentration and volume of the ith voxel respectively, and $N$ is the number of the voxels that contain agglomerate only, excluding the voxels in the thin ionomer film. For catalyst layer composed of non-overlapped spherical agglomerates with radius of $r_{\mathrm{gg}}$, and each sphere coated by a thin ionomer film $\delta$ nanometres thick and in direct 
contact with the oxygen in the macropores, the volumetric average reaction rate $R_{0}$ was analytically derived as follows (Epting and Litster, 2012):

$$
R_{0}=E_{r g g} k_{c} c_{0},
$$

where $c_{0}$ is the concentration of the dissolved oxygen at the outer surface of the thin ionomer film, and $E_{r g g}<1$ is an effectiveness factor defined as follows to describe the decrease in reaction rate due to diffusion limitation:

$$
\begin{aligned}
& E_{r g g}=\left(\frac{1}{E}+\frac{k_{c} r_{g g} \delta}{a_{g g}\left(r_{g g}+\delta\right) D_{0}}\right)^{-1}, \\
& E=\frac{1}{\Phi}\left(\frac{1}{\tanh (3 \Phi)}-\frac{1}{3 \Phi}\right), \\
& \Phi=\frac{r_{g g}}{3} \sqrt{\frac{k_{c}}{D_{e f f}}},
\end{aligned}
$$

where $D_{0}$ and $D_{\text {eff }}$ are diffusion coefficients of the dissolved oxygen in pure ionomer and in the agglomerates, respectively.

The above agglomerate model with a single radius $r_{g g}$ is an approximation of the real catalyst layer. For the real catalyst layer shown in Figure 3, we used a similar formula as follows to describe the reduced electrochemical reaction rate due to diffusion limitation:

$$
R_{0}=E_{A G G} k_{c} c_{0},
$$

where $E_{A G G}$ is also called effectiveness factor, but differs from $E_{r g g}$ defined in Equation (4) unless the agglomerates in a real catalyst layer reduce to non-overlapped equal spheres, and each sphere is coated by an isolated thin ionomer film which is in direct contact with the oxygen in the macropores. By equating Equations (3) and (6), the value of $E_{A G G}$ can be calculated from:

$$
E_{A G G}=\frac{\sum_{i=1}^{N} V_{i} c_{i} / c_{0}}{\sum_{i=1}^{N} V_{i}} .
$$


Equation (7) reduces to the homogenous model when oxygen concentration becomes uniform across the agglomerates and oxygen diffusion is no longer a limiting factor.

To quantify the accuracy of the spherical agglomerate model with a single diameter for describing the average reaction rate in the real catalyst layer, we defined the following error:

$$
\varepsilon=\frac{E_{r g g}-E_{A G G}}{E_{A G G}} 100 .
$$

To analyse the irregularity of the agglomerates shown in Figure 3, we calculated the agglomerate-size distribution assuming that the catalyst layer was composed of a number of overlapped spherical agglomerates. The agglomerate-size distribution is the relationship between the diameter of each inscribed sphere and the volume of the agglomerates that is just covered by this sphere without any macropores inside it.

\section{Results and discussion}

We first verified the numerical model against analytical solution for oxygen diffusion and reduction in a spherical agglomerate coated by a thin ionomer film shown in Figure 4A. The diameter of the sphere and the thickness of the ionomer film were $343 \mathrm{~nm}$ and $7.5 \mathrm{~nm}$, respectively. Figure 4B compares the effectiveness factors calculated from the pore-scale simulation with the analytical solution given by Equation (4) using the parameters shown in Table 1 . They agree well with a coefficient of determination $R=99.2 \%$, indicating that the numerical model is adequate to simulate oxygen diffusion and reaction in the agglomerates. This small discrepancy is due to the inherent truncation errors of the numerical model and the approximation that the smooth surface of the spherical agglomerate was approached by a zigzag surface as illustrated in Figure 4A.

In the real catalyst layer shown in Figure 3, the electrochemical reaction rate depends not only on the complicated agglomerate geometry, but also on volumetric ionomer content, overpotential and other electrochemical parameters shown in Table 1. The volumetric 
ionomer content affects the reaction rate because it controls the pathways for oxygen and proton to diffuse in the agglomerate (Passalacqua et al., 2001). The effective diffusion coefficient of the agglomerate for dissolved oxygen is often assumed to depend on its ionomer content $\theta$ in $D_{\text {eff }}=D_{o} \theta^{1.5}$. In all of the simulations, we assumed $\theta$ was 0.3 as this is close to the estimated optimal ionomer content (Wang et al., 2007). For a given ionomer content, another design parameter is catalyst loading. In mathematical models, the catalyst loading is often represented by the specific surface area of the catalyst, $S_{a}$. The value of $S_{a}$ reported in the literature is approximately in the range of $10^{7} \sim 10^{8}\left(\mathrm{~m}^{2} / \mathrm{m}^{3}\right)$ (Thiele et al., 2013). To examine the effect of catalyst loading on catalyst efficiency, we simulated oxygen diffusion and reaction under different specific surface areas in the microstructure shown in Figure 3. Figure 5 shows the change of the simulated effectiveness factor with overpotential under different catalyst loadings. It is evident that at high overpotential, the catalyst efficiency decreases as the catalyst loading increases.

The agglomerates in real catalyst layer are irregular, and the spherical agglomerate model with a single diameter is just an approximation in attempts to describe the average reaction rate in a representative volume of the catalyst layer. It is hence interesting to see if, for a given catalyst layer, an effective single diameter exists with which the spherical agglomerate model can effectively describe the average oxygen reduction rate across a range of overpotentials. In the literature, such effective diameters vary widely in the range from 200 nm to $6000 \mathrm{~nm}$ (Shah et al., 2006; Siegel et al., 2003). These are considerably higher than the diameter estimated from the images of real catalyst layers, which is approximately $100 \mathrm{~nm}$ (Epting and Litster, 2012). If the catalyst layer shown in Figure 3 was assumed to be composed of overlapped spheres, we can estimate the diameter of each sphere. Figure 6A shows the agglomerate-size distribution; the diameters of the spheres vary from a few nanometres to 175 nanometre with a mean of $87 \mathrm{~nm}$. This is smaller than the diameter 
estimated by Epting et al. (Epting and Litster, 2012) because the resolution of our image is 10 times higher than theirs. The volumetric oxygen reduction rate predicted from the spherical agglomerate model using this mean diameter is compared with the simulated results in Figure 7. It is obvious that the spherical model with the mean diameter considerably overestimated the reaction rate when overpotential is high, and the errors increased to $120 \%$ when the overpotential increased from $0.6 \mathrm{~V}$ to $0.95 \mathrm{~V}$.

Epting et al. (Epting and Litster, 2012) proposed a spherical agglomerate model with multiple spheres to approximate the catalyst layer, and the diameter of each sphere was obtained from the X-ray image of their catalyst layer. We also fitted their model to our simulated results with the diameter of each sphere and its associated volumetric fraction taken from Figure 6A. The errors of this multiple-diameter model are shown in Figure 7. It is evident that even using multiple spheres, the spherical agglomerate model still significantly overestimated the average reaction rate when the overpotential is high. This is anticipated as the spherical agglomerate model with multiple diameters assumed that all spheres are independent, and the surface of each sphere is coated by a thin ionomer film and the oxygen can diffuse from the macrospores into the sphere from all the directions. This is not what happens in real catalyst layer. For the catalyst layer shown in Figure 6B, even though it can be viewed as being comprised of a number of overlapped spheres, not all of the outer surfaces of these spheres are coated by the thin ionomer film and in contact with the oxygen in the macropores. The contact area for oxygen to diffuse from macrospores to agglomerates in a real catalyst layer is much smaller than assumed by the spherical model. For the catalyst layer shown in Figure 3, we calculated the contact area between the agglomerates and the macropores, and the result is $7.8 \times 10^{7} \mathrm{~m}^{2} / \mathrm{m}^{3}$. This contact area, however, would unrealistically increase to $1.33 \times 10^{9} \mathrm{~m}^{2} / \mathrm{m}^{3}$ if we approximate the catalyst layer by nonoverlapped spheres with a mean diameter of $87 \mathrm{~nm}$, and to $4.25 \times 10^{10} \mathrm{~m}^{2} / \mathrm{m}^{3}$ if we 
approximate it using the multiple spheres with their diameters and volumetric fraction estimated from Figure 6A. These exaggerated contact areas by the agglomerate models considerably overestimated the oxygen diffusion from the macrospores to the agglomerates. When oxygen transport becomes diffusion-limited, these unrealistic contact areas will overestimate the oxygen reduction rate and hence the catalyst efficiency.

In the literature, there is a significant difference between the agglomerate size measured from experiments and the agglomerate diameter used in the agglomerate models, with the former at least a few times smaller than the latter. This leads us to conjecture that the diameter in the agglomerate model is just a fitting parameter rather than a geometrical description of the agglomerates in real catalyst layers. Taking the diameter in the spherical agglomerate model as a fitting parameter (called effective diameter), we can fit the simulated results to the spherical agglomerate model. The value of the effective diameter, however, cannot be a constant, and has to increase with the overpotential in order to match the simulated data. Figure 8 shows the change of the effective diameter with the overpotential. For overpotential lower than $0.6 \mathrm{~V}$, since the electrochemical reaction is slow and the oxygen diffusion is not a limiting factor, the spherical agglomerate model is not sensitive to the effective diameter. With the overpotential increasing, however, the reaction rate increases and the diffusion gradually becomes a limiting factor. As a result, a local concentration gradient is generated in the agglomerate in which the pores distant from the outer surface of the agglomerate become less accessible to the oxygen. As an illustrative example, Figure 9 compares the oxygen distribution at a low overpotential $(0.6 \mathrm{~V})$ with that at a high overpotential $(0.85 \mathrm{~V})$; the diffusion limitation at the high overpotential is evident. If we use the spherical agglomerate model in such scenarios, the effective diameter of the model has to increase in order to correctly describe the tortuous paths along which the oxygen moves from the macropores into the irregular agglomerates. 
Our results revealed that when using the spherical agglomerate model to fit the simulated reaction rates, its effective diameter needs to increase with the overpotential in order to match the rates. This is in contradiction to the results of Epting et al. (Epting and Litster, 2012), which showed that the effective diameter deceased as the overpotential increased. This conflict is anticipated as the comparison of Epting et al.(Epting and Litster, 2012) was between a single-diameter agglomerate model and a multiple-diameter agglomerate model. The multiple-diameter model was assumed to be an accurate representation of the real catalyst layer, and the diameter of each sphere was estimated from the 3D image of their catalyst layer. The underlying assumption in this multiple-diameter model is that the catalyst layer is composed of a number of spheres, and each sphere is coated by a thin ionomer and works independently. As explained above, assuming the spheres working independently substantially overestimates the contact areas between the agglomerates and the macropores, exaggerating oxygen diffusion and reaction rate as a result. As illustrated in Figure 6B, even though the catalyst layer can be viewed as a composition of a number of spheres, majority of small spheres are not isolated; they are parts of large agglomerate clusters. Not all the surface areas of these small spheres are in contact with the oxygen in the macropores as presumed by the multiple-diameter agglomerate model. Therefore, the contribution of these small spheres to oxygen reduction rate is much less than estimated by assuming them working independently when oxygen diffusion becomes a limiting factor at high overpotential.

\section{Conclusions}

The agglomerate models with a single diameter have been, and might continue to be the most common approach to describe the average electrochemical reaction rate in the catalyst layer in PEM fuel cell modelling. Since the agglomerates in real catalyst layers are highly irregular, approximating them by independent spheres could give rise to considerable errors. 
In this paper, we investigated these errors based on nanotomography and pore-scale simulations. Three dimensional structure of a commercial catalyst layer was acquired using focused ion beam/scanning electron microscopy at resolution of five nanometres, and oxygen diffusion and reduction in the structure were then simulated at nanometre scale using a porescale model. The simulated oxygen concentration and reaction rate in all the voxels in the 3D image were then spatially averaged to obtain the volumetric average reaction rates. The simulated average reaction rates were then compared with the results predicted by the spherical agglomerate model with both single and multiple diameters with the diameter of the spheres estimated from the 3D image.

The purpose of this paper is to investigate the accuracy and reliability of the agglomerate model with a single or multiple diameters for describing the average electrochemical reaction rate. It is not to provide a comprehensive simulation of the transport and reaction processes in the catalyst layer. We therefore focused on a simple scenario in which the agglomerates were assumed to be fully filled by ionomer and the exterior surface of the agglomerates was assumed to be coated by a thin ionomer film; the macropores between the agglomerates were filled by air, and the gashouse oxygen in the macropores and the oxygen dissolved in the thin ionomer coating were assumed to be in equilibrium. Since both carbon and platinum in the agglomerates have a very good electronic conductivity and the resistance of the ionomer to proton transport is very small, the ohmic losses due to electron conduction and proton transport are both negligible (Gode et al., 2003; Wang et al., 2004a). As a result, the overpotential in the simulated agglomerates shown in Figure 3 was a constant. Under these conditions, our simulated results showed that the agglomerate model with a single or multiple diameters can only describe the average reaction rate when the overpotential is low. As the overpotential increased, the spherical agglomerate models 
overestimated the reaction rate, and their errors increased exponentially with the overpotential.

These findings suggest that the diameter in the spherical agglomerate model is just a fitting parameter rather than a geometrical description of the agglomerate; it depends on overpotential more than on agglomerates size. This partly explained why the diameter reported in the literature for the spherical agglomerate model varies so widely in the range from $200 \mathrm{~nm}$ to $6000 \mathrm{~nm}$ (Shah et al., 2006; Siegel et al., 2003), much larger than the average agglomerate diameter estimated from experiments (Thiele et al., 2013). This implicates that the spherical agglomerate models must be used with great care in catalyst layer design, especially for catalyst layers that will work at high overpotential, as a wrong interpretation of the agglomerate size in a design could lead to wrong results for catalyst loading and ionomer content.

The catalyst layer is an important component in PEM fuel cells, and numerical modelling plays an important role in its design. Given the inaccuracy of the simplified spherical model in calculating the electrochemical reaction at high overpotential, one can use tomography and pore-scale modelling to directly calculate the average electrochemical reaction rates inside the catalyst layer and then save the results in tabular form as input data to fuel cell modelling. This paper made such an effort. Although our simulations were limited to a simple isothermal scenario in that the catalyst layer was dry and the ohmic losses due to protons transport and electron conduction were negligible, expending the model to general conditions including liquid water and thermal conduction is possible. Work in these areas is under development, and how to integrate the results into fuel cell modelling will be reported in future publications.

\section{Acknowledgements}


This research was supported by the UK Technology Strategy Board (TSB Project No.

TP/6/S/K3032H). We acknowledge the two anonymous reviewers for their comments to improve the manuscript. We also thank Dr. Hutzenlaub for sharing his FIB/SEM image. 


\section{References}

Balgis, R., Anilkumar, G.M., Sago, S., Ogi, T., Okuyama, K., 2012. Nanostructured design of electrocatalyst support materials for high-performance PEM fuel cell application. J. Power Sources, 203: 26-33.

Broka, K., Ekdunge, P., 1997. Modelling the PEM fuel cell cathode. Journal of Applied Electrochemistry, 27(3): 281-289.

Das, P.K., Li, X.G., Liu, Z.S., 2008. A three-dimensional agglomerate model for the cathode catalyst layer of PEM fuel cells. J. Power Sources, 179(1): 186-199.

El Hannach, M., Prat, M., Pauchet, J., 2012. Pore network model of the cathode catalyst layer of proton exchange membrane fuel cells: Analysis of water management and electrical performance. Int. J. Hydrog. Energy, 37(24): 18996-19006.

Epting, W.K., Gelb, J., Litster, S., 2012. Resolving the Three-Dimensional Microstructure of Polymer Electrolyte Fuel Cell Electrodes using Nanometer-Scale X-ray Computed Tomography. Adv. Funct. Mater., 22(3): 555-560.

Epting, W.K., Litster, S., 2012. Effects of an agglomerate size distribution on the PEFC agglomerate model. Int. J. Hydrog. Energy, 37(10): 8505-8511.

Gloaguen, F., Durand, R., 1997. Simulations of PEFC cathodes: an effectiveness factor approach. Journal of Applied Electrochemistry, 27(9): 1029-1035.

Gode, P., Jaouen, F., Lindbergh, G., Lundblad, A., Sundholm, G., 2003. Influence of the composition on the structure and electrochemical characteristics of the PEFC cathode. Electrochim. Acta, 48(28): 4175-4187.

Harvey, D., Pharoah, J.G., Karan, K., 2008. A comparison of different approaches to modelling the PEMFC catalyst layer. Journal of Power Sources, 179(1): 209-219.

Hutzenlaub, T., Becker, J., Zengerle, R., Thiele, S., 2013. Modelling the water distribution within a hydrophilic and hydrophobic 3D reconstructed cathode catalyst layer of a proton exchange membrane fuel cell. J. Power Sources, 227: 260-266.

Joos, J., Ender, M., Carraro, T., Weber, A., Ivers-Tiffee, E., 2012. Representative volume element size for accurate solid oxide fuel cell cathode reconstructions from focused ion beam tomography data. Electrochim. Acta, 82: 268-276.

Kamarajugadda, S., Mazumder, S., 2008. Numerical investigation of the effect of cathode catalyst layer structure and composition on polymer electrolyte membrane fuel cell performance. Journal of Power Sources, 183(2): 629-642.

Kamarajugadda, S., Mazumder, S., 2012. Generalized flooded agglomerate model for the cathode catalyst layer of a polymer electrolyte membrane fuel cell. Journal of Power Sources, 208: 328-339.

Lange, K.J. et al., 2012. PEM fuel cell CL characterization using a standalone FIB and SEM: Experiments and simulation. Electrochim. Acta, 85: 322-331.

Liu, F.Q. et al., 2003. Development of novel self-humidifying composite membranes for fuel cells. J. Power Sources, 124(1): 81-89.

Moein-Jahromi, M., Kermani, M.J., 2012. Performance prediction of PEM fuel cell cathode catalyst layer using agglomerate model. Int. J. Hydrog. Energy, 37(23): 17954-17966.

Ostadi, H. et al., 2010. 3D reconstruction of a gas diffusion layer and a microporous layer. J. Membr. Sci., 351(1-2): 69-74.

Passalacqua, E., Lufrano, F., Squadrito, G., Patti, A., Giorgi, L., 2001. Nafion content in the catalyst layer of polymer electrolyte fuel cells: effects on structure and performance. Electrochim. Acta, 46(6): 799-805.

Porta, G., Chaynikov, S., Riva, M., Guadagnini, A., 2013. Upscaling solute transport in porous media from the pore scale to dual- and multicontinuum formulations. Water Resources Research, 49(4): 2025-2039. 
Shah, A.A. et al., 2006. The effects of water and microstructure on the performance of polymer electrolyte fuel cells. Journal of Power Sources, 160(2): 1251-1268.

Siddique, N.A., Liu, F.Q., 2010. Process based reconstruction and simulation of a threedimensional fuel cell catalyst layer. Electrochim. Acta, 55(19): 5357-5366.

Siegel, N.P., Ellis, M.W., Nelson, D.J., von Spakovsky, M.R., 2003. Single domain PEMFC model based on agglomerate catalyst geometry. Journal of Power Sources, 115(1): 8189.

Sun, W., Peppley, B.A., Karan, K., 2005. An improved two-dimensional agglomerate cathode model to study the influence of catalyst layer structural parameters. Electrochim. Acta, 50(16-17): 3359-3374.

Suzuki, T., Kudo, K., Morimoto, Y., 2013. Model for investigation of oxygen transport limitation in a polymer electrolyte fuel cell. Journal of Power Sources, 222: 379-389.

Thiele, E.W., 1939. Relation between catalytic activity and size of particle. Industrial and Engineering Chemistry, 31: 916-920.

Thiele, S. et al., 2013. Multiscale tomography of nanoporous carbon-supported noble metal catalyst layers. J. Power Sources, 228: 185-192.

Thiele, S., Zengerle, R., Ziegler, C., 2011. Nano-morphology of a polymer electrolyte fuel cell catalyst layer-imaging, reconstruction and analysis. Nano Research, 4(9): 849-860.

Wang, G.Q., Mukherjee, P.P., Wang, C.Y., 2007. Optimization of polymer electrolyte fuel cell cathode catalyst layers via direct numerical simulation modeling. Electrochim. Acta, 52(22): 6367-6377.

Wang, Q.P., Eikerling, M., Song, D.T., Liu, Z.S., 2004a. Structure and performance of different types of agglomerates in cathode catalyst layers of PEM fuel cells. J. Electroanal. Chem., 573(1): 61-69.

Wang, Q.P., Song, D.T., Navessin, T., Holdcroft, S., Liu, Z.S., 2004b. A mathematical model and optimization of the cathode catalyst layer structure in PEM fuel cells. Electrochim. Acta, 50(2-3): 725-730.

Wang, Y., Chen, K.S., Mishler, J., Cho, S.C., Adroher, X.C., 2011. A review of polymer electrolyte membrane fuel cells: Technology, applications, and needs on fundamental research. Appl. Energy, 88(4): 981-1007.

Wargo, E.A., Schulz, V.P., Cecen, A., Kalidindi, S.R., Kumbur, E.C., 2013. Resolving macro- and micro-porous layer interaction in polymer electrolyte fuel cells using focused ion beam and X-ray computed tomography. Electrochim. Acta, 87: 201-212.

Wu, R., Liao, Q., Zhu, X., Wang, H., 2012. Pore network modeling of cathode catalyst layer of proton exchange membrane fuel cell. Int. J. Hydrog. Energy, 37(15): 11255-11267.

Xia, Z.T., Wang, Q.P., Eikerling, M., Liu, Z.S., 2008. Effectiveness factor of Pt utilization in cathode catalyst layer of polymer electrolyte fuel cells. Canadian Journal of Chemistry-Revue Canadienne De Chimie, 86(7): 657-667.

Yu, X., Yuan, J.L., Sunden, B., 2011. Review on the Properties of Nano-/Microstructures in the Catalyst Layer of PEMFC. J. Fuel Cell Sci. Technol., 8(3).

Zhang, S.S. et al., 2009. A review of platinum-based catalyst layer degradation in proton exchange membrane fuel cells. J. Power Sources, 194(2): 588-600.

Zhang, X.X., Qi, X.B., Qiao, D.M., 2010. Change in macroscopic concentration at the interface between different materials: Continuous or discontinuous. Water Resour. Res., 46.

Ziegler, C., Thiele, S., Zengerle, R., 2011. Direct three-dimensional reconstruction of a nanoporous catalyst layer for a polymer electrolyte fuel cell. J. Power Sources, 196(4): 2094-2097.

Zils, S. et al., 2010. 3D Visualisation of PEMFC Electrode Structures Using FIB Nanotomography. Fuel Cells, 10(6): 966-972. 
Table 1 Physical properties and constant parameters used in the simulations

\begin{tabular}{|l|l|}
\hline \multicolumn{1}{|c|}{ Parameter } & \multicolumn{1}{|c|}{ Value } \\
\hline Cell temperature $(\mathrm{K})$ & 323.15 \\
\hline Volumetric fraction of ionomer (\%) & 30 \\
\hline Oxygen diffusion coefficient in ionomer $\left(\mathrm{m}^{2} \mathrm{~s}^{-1}\right)$ & $8.45 \times 10^{-10}$ \\
\hline Oxygen reference concentration $\left(\mathrm{mol} \mathrm{m}^{-3}\right)$ & 0.85 \\
\hline Reference exchange current density $\left(\mathrm{A} \mathrm{m}^{-2}\right)$ & $1.5 \times 10^{-2} \quad \mathrm{~V}<0.8$ \\
& $3.85 \times 10^{-6} \quad \mathrm{~V}>0.8$ \\
\hline Cathode transfer coefficient & $0.61 \mathrm{~V}<0.8 ;$ \\
& $1.0 \mathrm{~V}>0.8 \quad$ \\
\hline Electrochemically active surface area $\left(\mathrm{m}^{2} \mathrm{~m}^{-3}\right)$ & $1.04 \times 10^{7} \sim 1.04 \times 10^{8}$ \\
\hline Faraday constant $\left(\mathrm{C} \mathrm{mol}^{-1}\right)$ & 96485 \\
\hline Gas constant $\left(\mathrm{J} \mathrm{mol}^{-1} \mathrm{~K}^{-1}\right)$ & 8.314 \\
\hline
\end{tabular}




\section{Figure captions}

Figure 1. The configuration of FIB/SEM nanotomography. A cubic fiducial mark is milled first. Then the sample is milled in $10 \mathrm{~nm}$ thickness before an SEM image of the sample is taken. This milling-imaging cycle is repeated and over a hundred of SEM images are collected. The sectioning direction was perpendicular to FIB column. The images were aligned in reference to the fiducial mark and assembled into a 3D object. FIB window is shown in dashed line. With this configuration the small fiducial mark is protected against FIB bombardment.

Figure 2. Two illustrative images acquired using the FIB/SEM technology. Anode catalyst layer (A), and cathode catalyst layer (B).

Figure 3. The microstructure used for the simulation: 2D slice $\left(1 \times 1 \mu \mathrm{m}^{2}\right)(\mathrm{A})$, and 3D structure $\left(1 \times 1 \times 1 \mu \mathrm{m}^{3}\right)(\mathrm{B})$. Red is the ionomer film, green is the agglomerates, and blue is the macropores. The macropores in the $3 \mathrm{D}$ structure are made transparent.

Figure 4. The spherical agglomerate (343nm in diameter, and coated by7.5nm of ionomer) used to validate the numerical model (A). Comparison between the numerically simulated (symbols) and the analytical (solid line) effectiveness factors for the spherical agglomerate using the parameters shown Table 1.

Figure 5. Change of the effectiveness factor with overpotential under different catalyst loadings.

Figure 6. The agglomerate-size distribution estimated from the 3D image shown in Figure 3(A). 2D slice showing the overlapping of the spheres with different diameters (nm) that constitute the catalyst layer (B).

Figure 7. Errors of the spherical agglomerate models with a single mean diameter and multiple diameters taken from Figure 6A.

Figure 8. Increase of the effective agglomerate diameter with overpotential when using the spherical agglomerate model to fit the simulated reaction rates with the parameters shown in Table 1 and $S_{a}=1.04 \times 10^{7} \mathrm{~m}^{2} / \mathrm{m}^{3}$.

Figure 9. Distribution of the normalized oxygen concentrations $\left(\mathrm{c} / \mathrm{c}_{0}\right)$ in the catalyst layer under overpotential of $0.65 \mathrm{~V}(\mathrm{~A})$ in comparison with that under overpotential of $0.85 \mathrm{~V}$ (B). The value of the normalised concentration changes from 1 (red) to 0.05 (blue). 


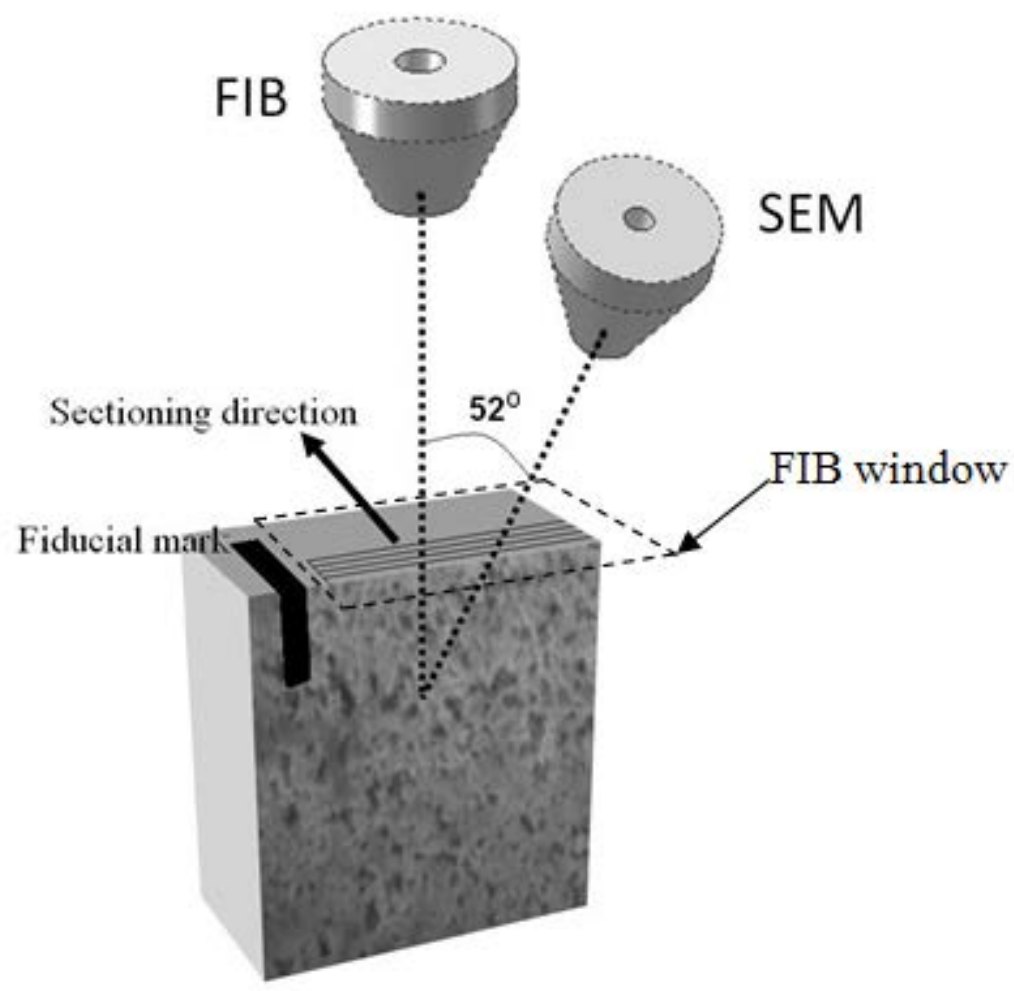

Figure 1. The configuration of FIB/SEM nanotomography. A cubic fiducial mark is milled first. Then the sample is milled in $10 \mathrm{~nm}$ thickness before an SEM image of the sample is taken. This milling-imaging cycle is repeated and over a hundred of SEM images are collected. The sectioning direction was perpendicular to FIB column. The images were aligned in reference to the fiducial mark and assembled into a 3D object. FIB window is shown in dashed line. With this configuration the small fiducial mark is protected against FIB bombardment. 


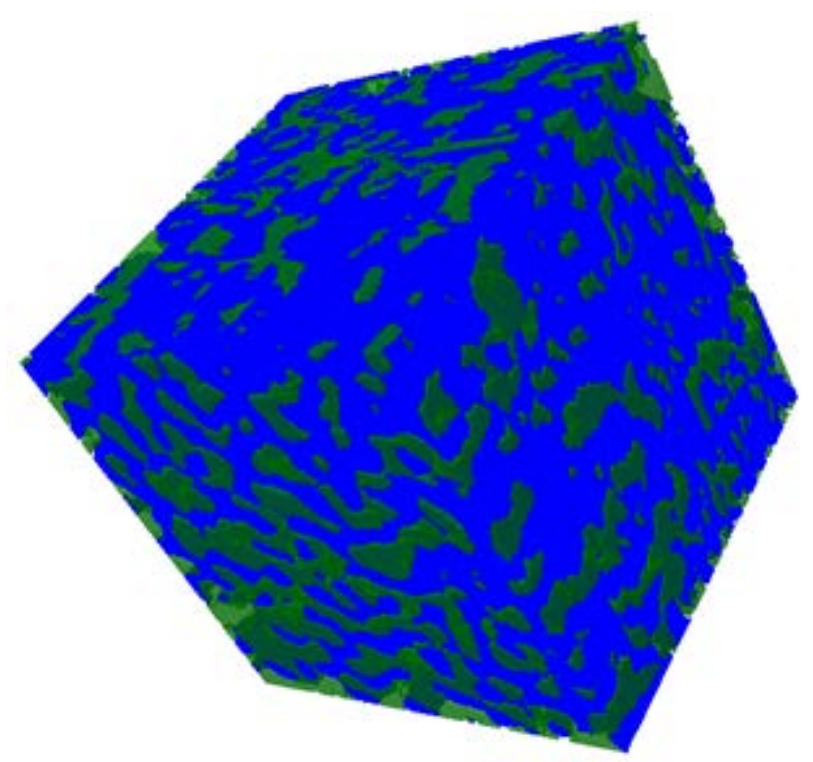

(A)

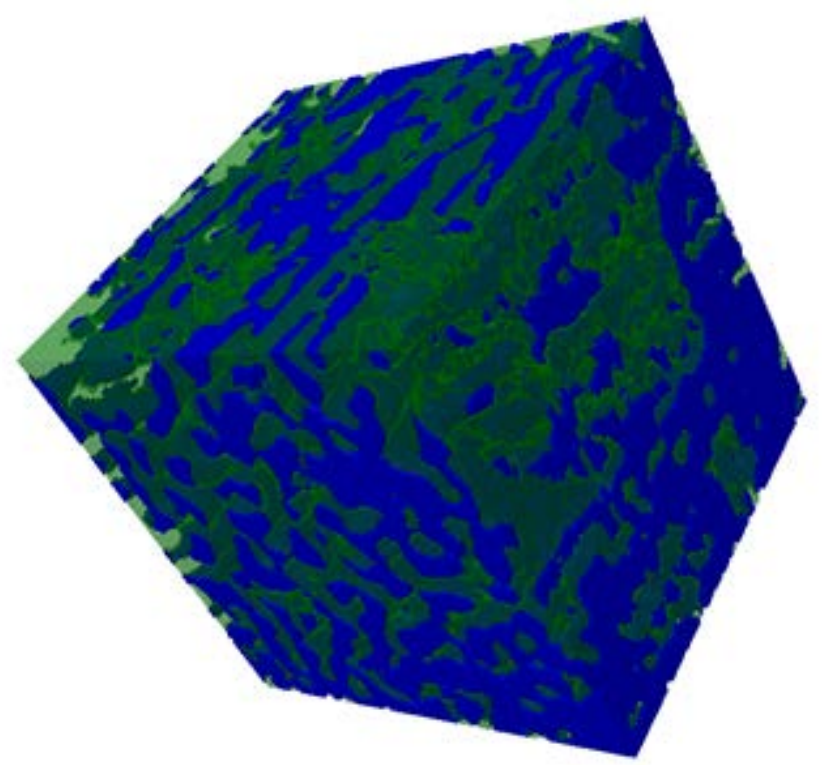

(B)

Figure 2. The image acquired using FIB/SEM. (A) Catalyst layer before electrical test, and (B) catalyst layer after the electrical test. 


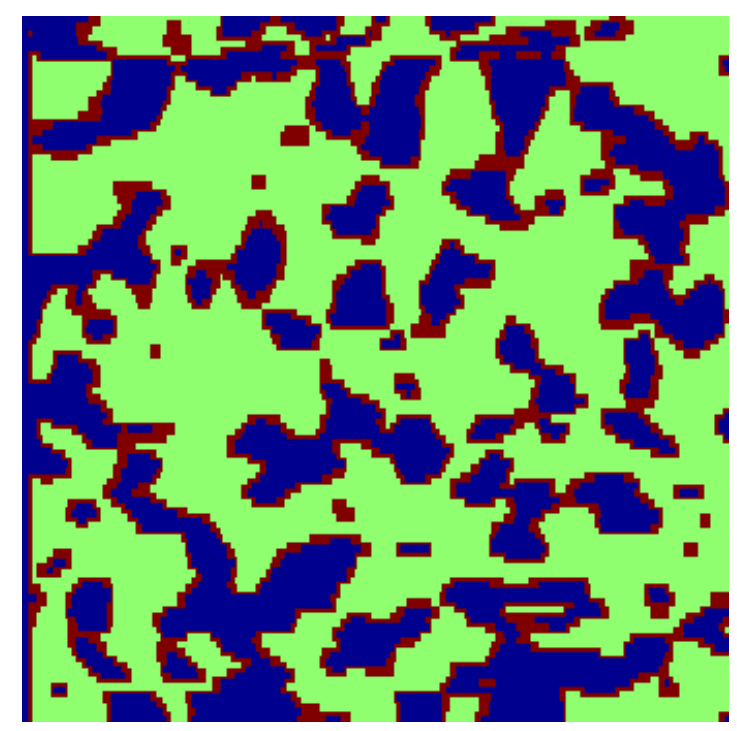

(A)

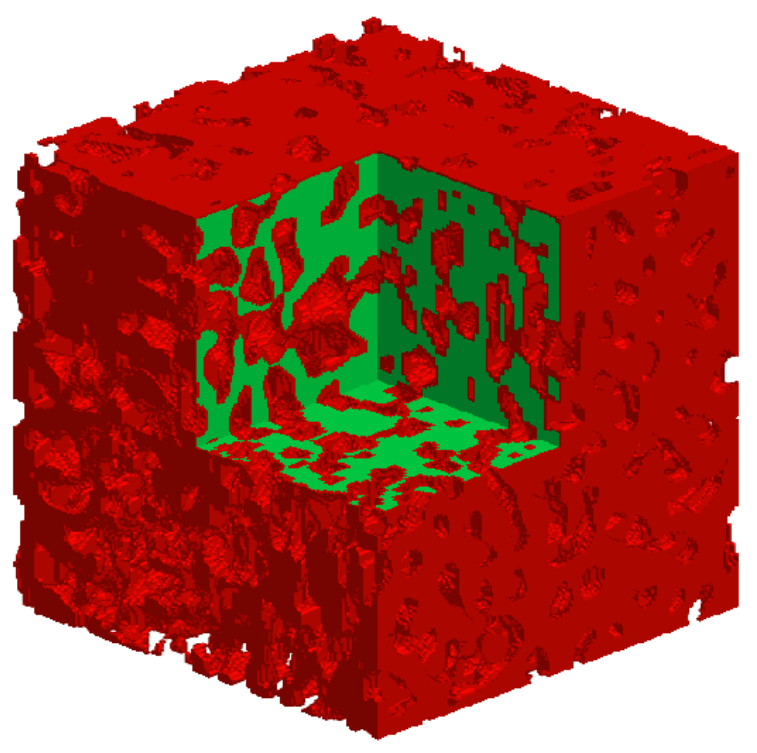

(B)

Figure 3. The microstructure used for the simulation: 2D slice $\left(1 \times 1 \mu \mathrm{m}^{2}\right)(\mathrm{A})$, and $3 \mathrm{D}$ structure $\left(1 \times 1 \times 1 \mu \mathrm{m}^{3}\right)(\mathrm{B})$. Red is the ionomer film, green is the agglomerates, and blue is the macropores. The macropores in the 3D structure are made transparent. 


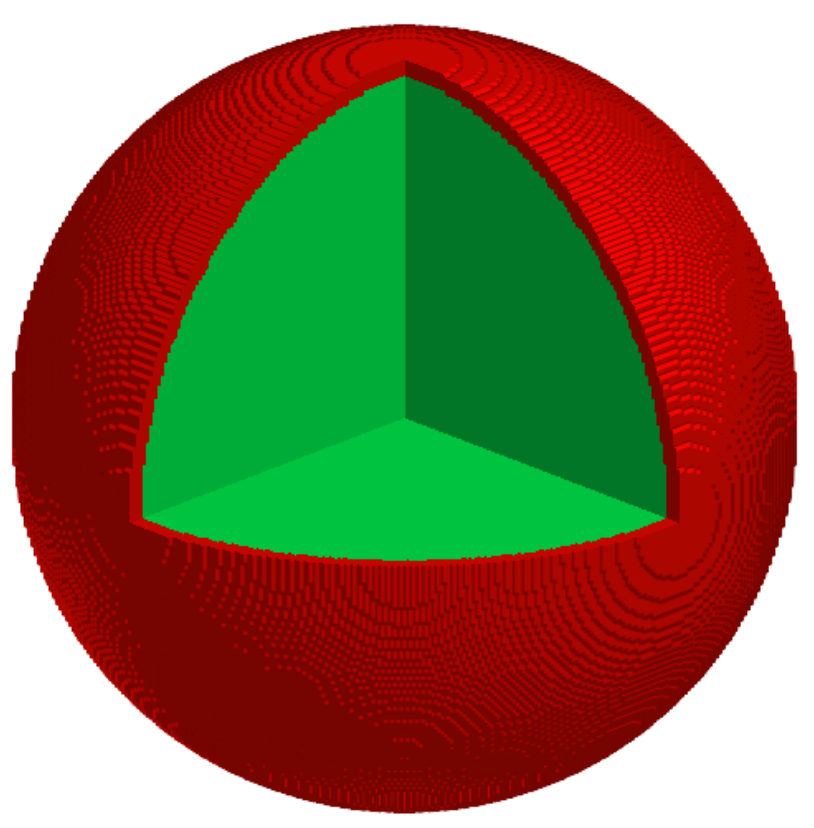

(A)

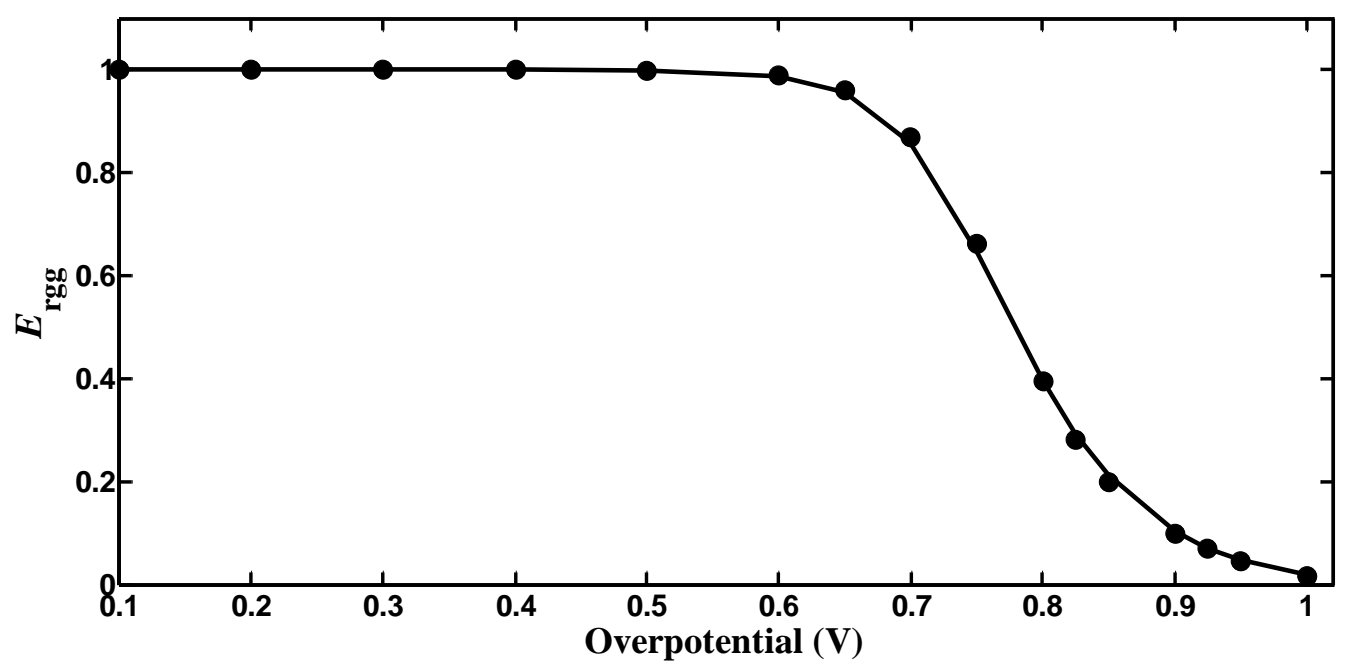

(B)

Figure 4. The spherical agglomerate (343nm in diameter, and coated by7.5nm of ionomer) used to validate the numerical model (A). Comparison between the numerically simulated (symbols) and the analytical (solid line) effectiveness factors for the spherical agglomerate using the parameters shown Table 1. 


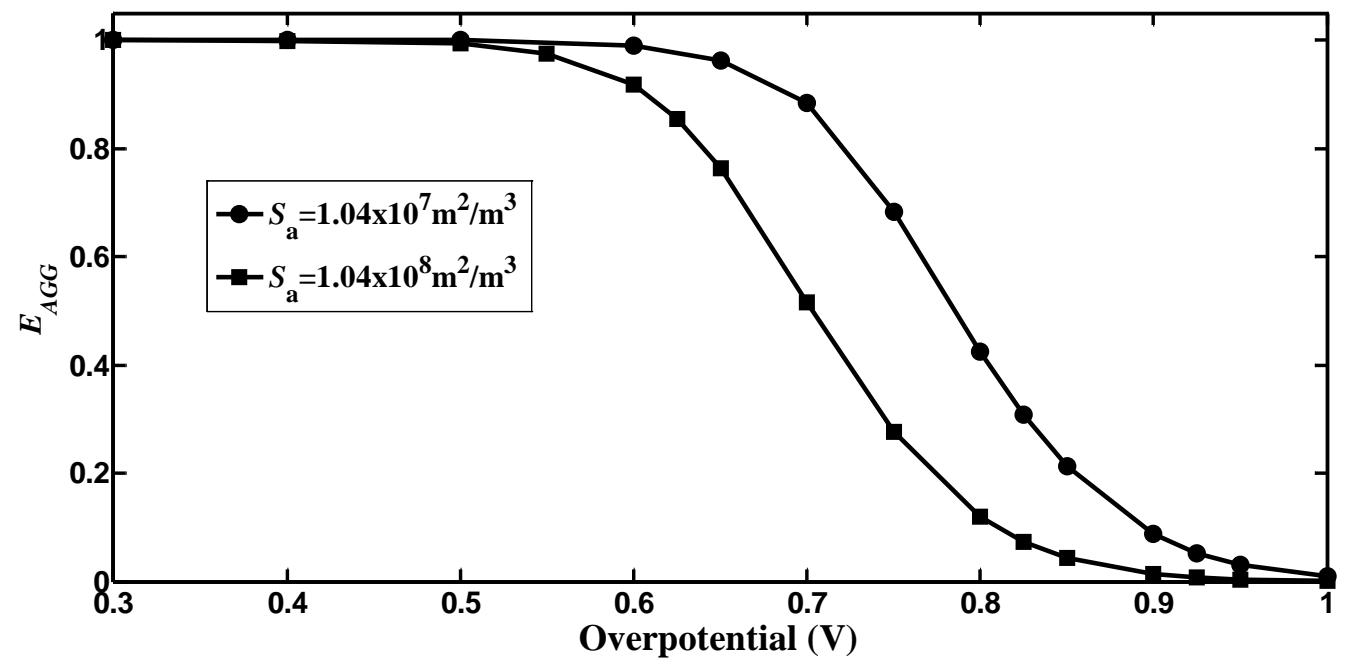

Figure 5. Change of the effectiveness factor with overpotential under different catalyst loadings. 


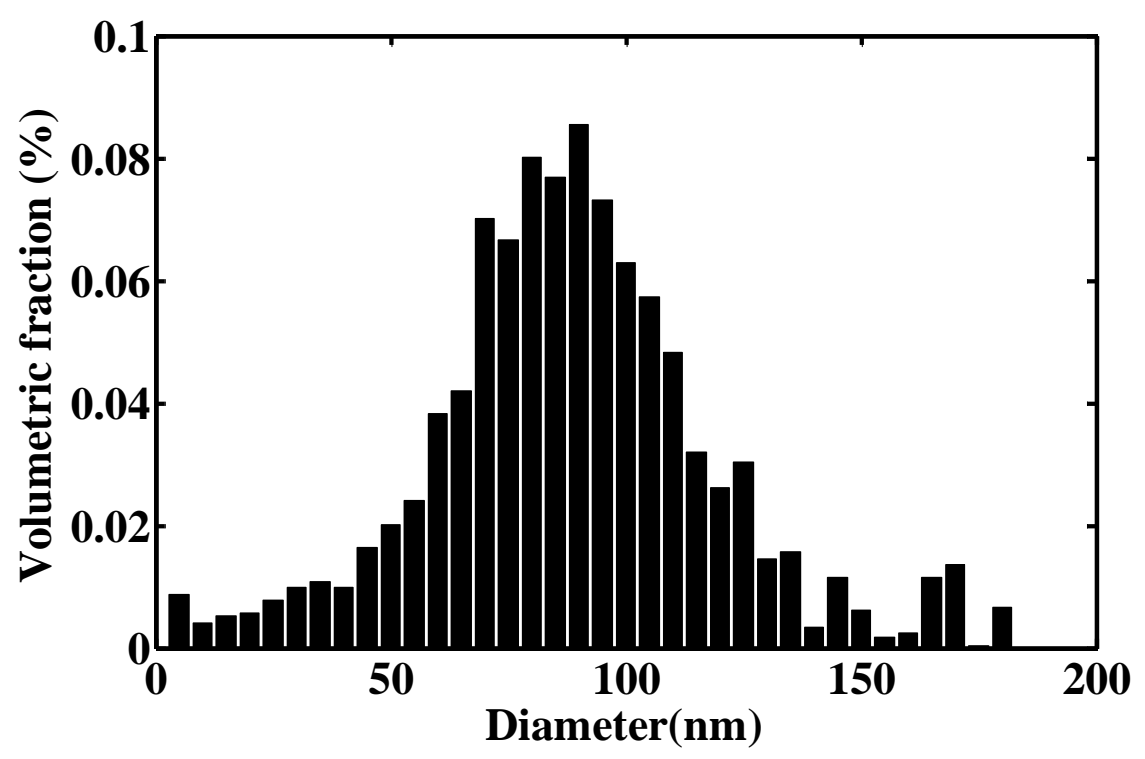

(A)

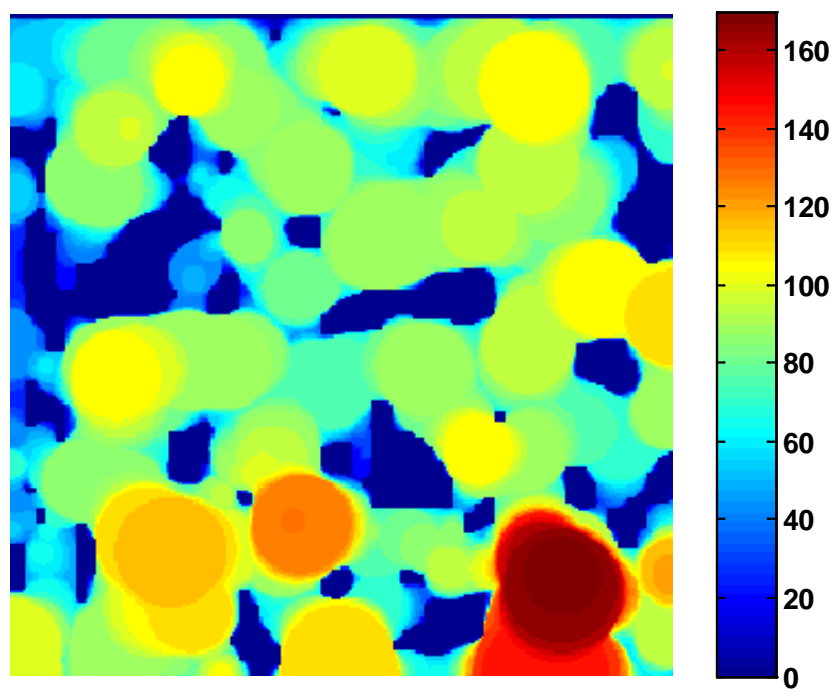

(B)

Figure 6. The agglomerate-size distribution estimated from the 3D image shown in Figure 3(A). 2D slice showing the overlapping of the spheres with different diameters (nm) that constitute the catalyst layer (B). 


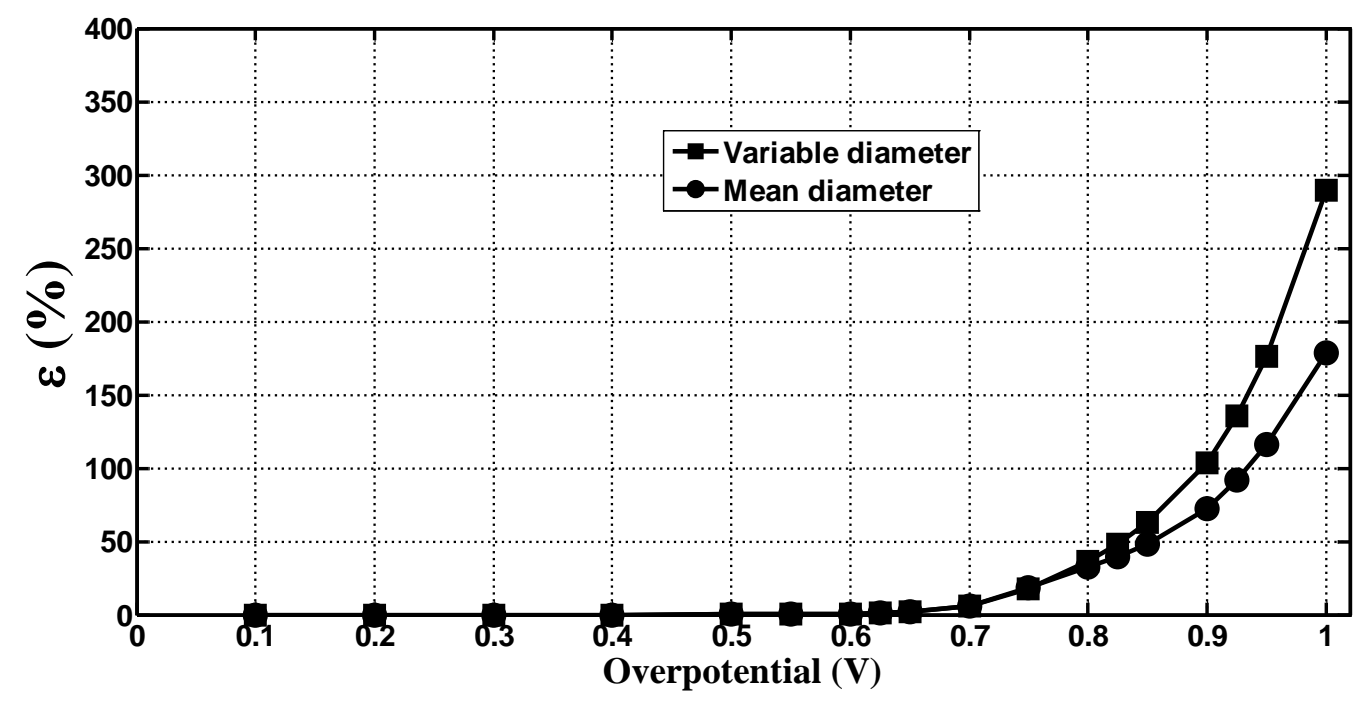

Figure 7. Errors of the spherical agglomerate models with a single mean diameter and multiple diameters taken from Figure 6A. 


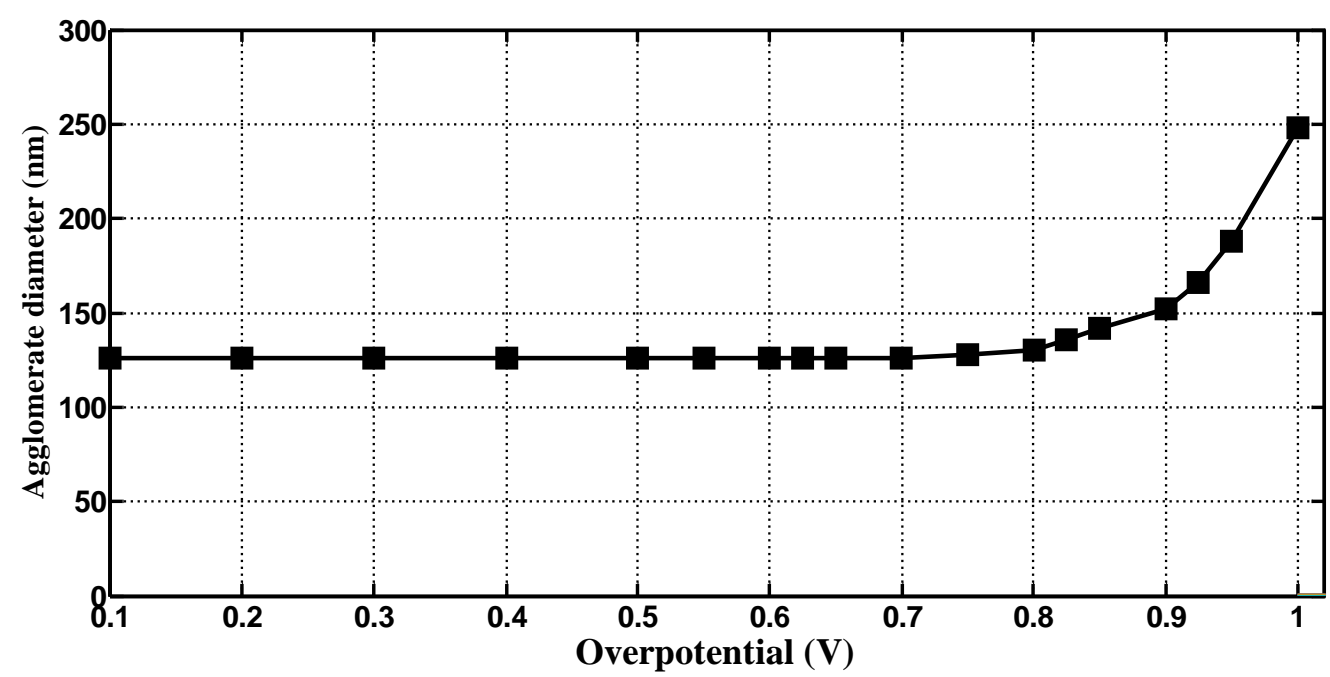

Figure 8. Increase of the effective agglomerate diameter with overpotential when using the spherical agglomerate model to fit the simulated reaction rates with the parameters shown in Table 1 and $S_{a}=1.04 \times 10^{7} \mathrm{~m}^{2} / \mathrm{m}^{3}$. 


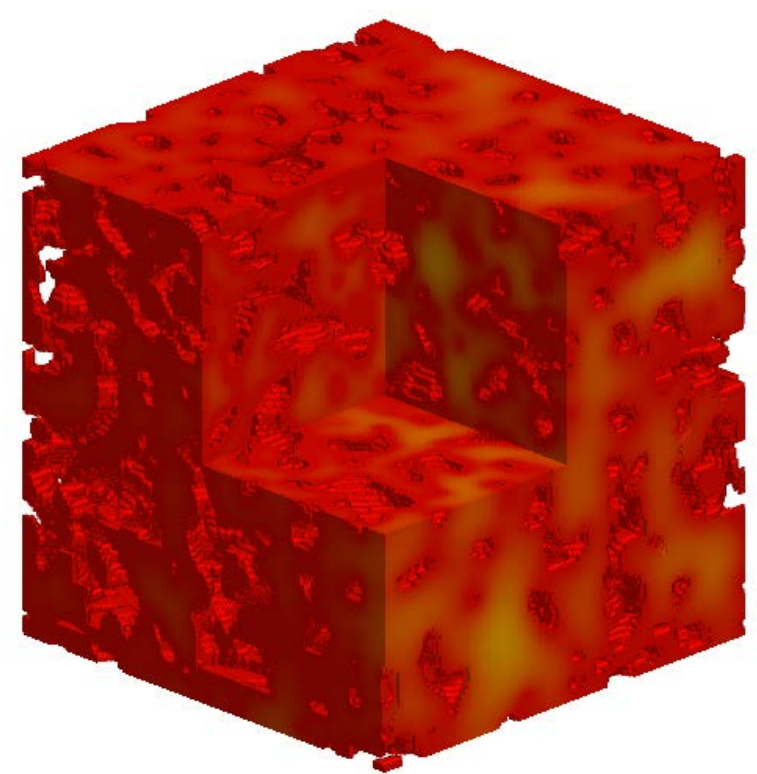

(A)

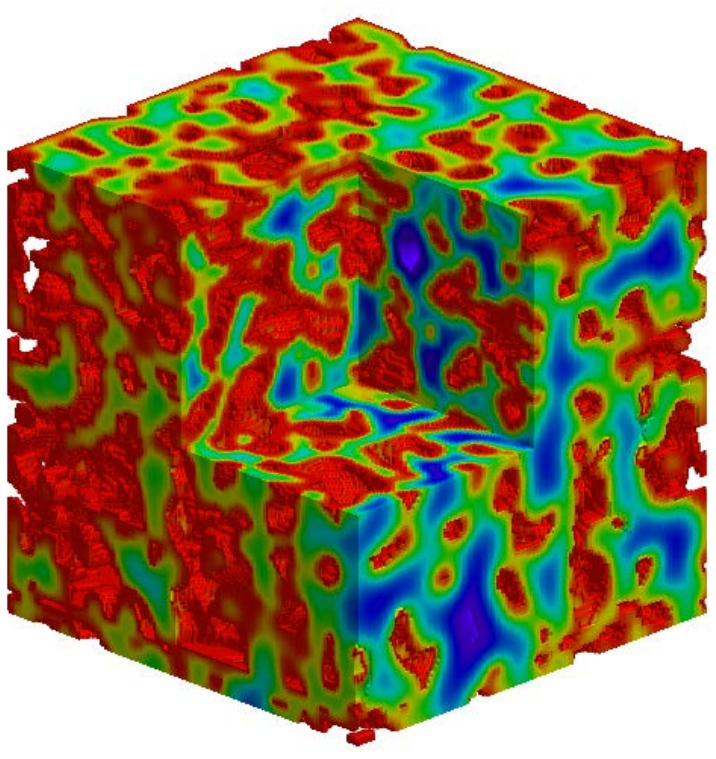

(B)

Figure 9. Distribution of the normalized oxygen concentrations $\left(\mathrm{c} / \mathrm{c}_{0}\right)$ in the catalyst layer under overpotential of $0.65 \mathrm{~V}(\mathrm{~A})$ in comparison with that under overpotential of $0.85 \mathrm{~V}$ (B). The value of the normalised concentration changes from 1 (red) to 0.05 (blue). 